Article

\title{
Comparison of the Effects Caused by Three Different Mandibular Advancement Devices on the Periodontal Ligaments and Teeth for the Treatment of Osa: A Finite Element Model Study
}

\author{
Giovanni Bruno ${ }^{1, *(1)}$, Alberto de Stefani ${ }^{1, *}\left(\mathbb{D}\right.$, Manila Caragiuli ${ }^{2}$, Francesca Zalunardo ${ }^{1}$, \\ Alida Mazzoli ${ }^{3}$, Daniele Landi ${ }^{2}$, Marco Mandolini ${ }^{2}$ (I) and Antonio Gracco ${ }^{1}$ \\ 1 Department of Neuroscience, Section of Dentistry, University of Padua, 35100 Padua, Italy; \\ zalunardo.francesca@gmail.com (F.Z.); antonio.gracco@unipd.it (A.G.) \\ 2 Department of Industrial Engineering and Mathematical Sciences, Università Politecnica delle Marche, \\ 60131 Ancona, Italy; m.caragiuli@staff.univpm.it (M.C.); d.landi@staff.univpm.it (D.L.); \\ m.mandolini@staff.univpm.it (M.M.) \\ 3 Department of Materials, Environmental Sciences and Urban Planning, Università Politecnica delle Marche, \\ via Brecce Bianche 12,60131 Ancona, Italy; a.mazzoli@staff.univpm.it \\ * Correspondence: giobruno93@gmail.com (G.B); alberto.de.stefani@hotmail.it (A.d.S.)
}

Received: 29 July 2020; Accepted: 27 September 2020; Published: 3 October 2020

check for updates

\begin{abstract}
AIM: The purpose of this study is to compare the stress effects developed on the periodontal ligaments and teeth by three different types of mandibular advancement devices (MADs) using a finite element method (FEM) analysis. Introduction: Obstructive sleep apnea (OSA) is a disease with a high prevalence and, in recent years, the use of MADs as an alternative or support treatment to the continuous positive airway pressure (CPAP) has spread. Their use finds relative contraindications in the case of partial edentulism and severe periodontal disease. Given the widespread of periodontal problems, it is essential to know the effects that these devices cause on the periodontal ligament of the teeth. Materials and methods: Starting from the computed tomography (CT) scan of a patient's skull, 3D reconstructions of the maxilla and mandible were implemented. Three different MADs were prepared for the patient, then 3D scanned, and lastly, coupled with the 3D models of the jaws. The devices have two different mechanics: One has a front reverse connecting rod (Orthoapnea ${ }^{\mathrm{TM}}$ ), and two have lateral propulsion (Somnodent ${ }^{\mathrm{TM}}$ and Herbst ${ }^{\mathrm{TM}}$ ). A FEM analysis was performed to calculate the stress applied on periodontal ligaments, on every single tooth and the displacement vectors that are generated by applying an advancement force on the mandible. Results: Herbst ${ }^{\mathrm{TM}}$ and Somnodent ${ }^{\mathrm{TM}}$ devices present very similar stress values, mainly concentrated on lateral teeth, but in general, the forces are very mild and distributed. The maximum stresses values are $3.27 \mathrm{kPa}$ on periodontal ligaments and $287 \mathrm{kPa}$ on teeth for Somnodent ${ }^{\mathrm{TM}}$ and $3.56 \mathrm{kPa}$ on periodontal ligaments and $302 \mathrm{kPa}$ on teeth for Herbst ${ }^{\mathrm{TM}}$. Orthoapnea ${ }^{\mathrm{TM}}$ has, instead, higher and concentrated stress values, especially in the anterior maxillary and mandibular area with $4.26 \mathrm{kPa}$ and $600 \mathrm{kPa}$ as maximum stress values, respectively, on periodontal ligaments and teeth. Conclusions: From the results, it is concluded that devices with a bilateral mechanism generate less and more distributed stress than an anterior connecting rod mechanism. Therefore, they may be advisable to patients with compromised periodontal conditions in the anterior area.
\end{abstract}

Keywords: dental materials; orthodontics; obstructive sleep apnea; mandibular advancement device; finite element method 


\section{Introduction}

Obstructive sleep apnea (OSA) is characterized by various and recurring episodes of reduction (hypopnea) or cessation (apnea) of the airflow during sleep. It results from the obstruction due to the collapse of the upper airway [1]. The pathophysiology of OSA is multifactorial and includes a reduction in upper airway dimensions that is caused by both anatomical and functional alterations (obesity or maxillofacial structural changes) and increased pharyngeal collapsibility due to reduced neuromuscular compensation and lack of the pharyngeal protective reflex during sleep [2-6].

OSA is one of the most prevalent chronic respiratory disorders. In recent population-based studies, the estimated prevalence of moderate to severe sleep-disordered breathing ranges from $3 \%$ to nearly $50 \%$ depending on the age group and sex. Recent studies suggest an increase in the incidence that is probably related to the growing prevalence of overweight and obese individuals $[7,8]$.

Extensive population-based studies have shown that untreated moderate or severe OSA is associated with severe complications. The most important are the increased cardiovascular and cerebrovascular disease, stroke, chronic inflammation, hypertension, and metabolic syndrome resulting in increased morbidity and mortality. The main symptoms are snoring, day sleepiness, nocturia, frequent nocturnal waking caused by choking or gasping sensations, psychological or cognitive dysfunction, morning headaches, low concentration, irritability, and erectile dysfunction. Many patients report a reduction in their life quality due to obstructive sleep apnea [9-13].

OSA is an under-estimated problem even though there are many screening tools such as the STOP-BANG questionnaire, Epworth scale, and Berlin questionnaire [14-17]. The gold standard for the diagnosis of OSA is polysomnography (level I study), which consists of an instrumental examination carried out in dedicated structures.

Polysomnography involves the collection of seven or more data channels, including respiratory, electrocardiogram, electroencephalogram, and electrooculogram for sleep staging and electromyogram. Another solution for the diagnosis is the home-based polygraphy [18-20].

CPAP (continuous positive airway pressure) is the gold standard treatment for severe OSA, but since the 1980s, even mandibular advancement devices (MADs) were used as a therapy for OSA. MADs are widely used for mild and moderate OSA treatment, and several studies have demonstrated their effectiveness even in the treatment of severe OSA [21,22]. MADs present higher compliance and are more convenient for the patient than CPAP [23-27].

Although mandibular advancement devices represent the gold standard in the treatment of mild and moderate OSA, they cause skeletal and dental modifications due to their use [28].

MADs are responsible for a small but statistically significant change in the dentition of long-term wearers. Skeletal changes are generally secondary to dental changes. Major dental modifications feature the tendency towards a reduction of overbite and overjet, maxillary incisors palatal tipping and mandibular incisor labial tipping. A moderate linkage exists between the length of treatment time (how long the device is worn), and the number of dental changes experienced [29].

Even if the modifications are not significant compared to the benefits that the use of the MAD brings, it is crucial to evaluate the periodontal consequences of these devices. Periodontal health is defined to be a state free from inflammatory periodontal disease. This situation, in turn, means that absence of inflammation associated with gingivitis or periodontitis [30]. An analysis of the literature reveals an epidemiological picture of the uneven periodontal disease with methodological discrepancies that make it difficult to compare the prevalence and severity of data [31].

In 2007, the Centers for Disease Control and Prevention and the American Academy of Periodontology determined that population-based epidemiological studies should use the definition of moderate and severe periodontitis proposed by Page and Eke [32]. In the European area, the prevalence of moderate periodontitis is between $33.3 \%$ and $50 \%$, while the severe one is between $17.6 \%$ and $35 \%$ [33-35]. Periodontal disease is a prevalent problem; it is estimated that more than $46 \%$ of the population in the United States is affected. The advanced forms of periodontitis that result in severe loss of supporting structures and substantial tooth loss affect $8.9 \%$ of the population [36]. 
The American Academy of Sleep Medicine stated that edentulism and severe periodontal disease represent a counter indication to the use of MADs. However, it is not verified how the stresses related to wearing MADs are discharged on the periodontal ligament of teeth [37].

Ethical or instrumental limits and increased complexity often put a limitation to research, and many questions cannot be answered given the impossibility of obtaining satisfactory results. In these cases, reverse engineering (RE) with the finite element method (FEM) represents a solution. RE is a technique used to generate a 3D virtual model from a real-world tangible object. FEM is an engineering instrument used to calculate stress and deformations in complex structures and has been widely applied in biomedical research. In the field of structural engineering, the use of FEM aims to establish the state of tension and deformation of a solid subjected to external actions.

By taking advantage of this engineering resource in orthodontics, it is possible to model and analyze any dental and maxillofacial material or structure [38]. The FEM principle is based on the division of complex structures into smaller sections called elements in which physical properties are applied to study the response of the object to external stimulation such as an orthodontic force. All this represents a significant advantage since the degree of simplification can be controlled.

The study aims to analyze how different types of MADs stress and deform teeth and periodontal ligaments of the individual dental elements of both arches, using a finite element method analysis. To the author's knowledge, this is the first work that compares the effects of three different types of MADs through a FEM. The predictable behavior of teeth and periodontal ligaments (PDLs) suggests to the clinicians the choice of the most suitable OSA treatment device depending on the patient's dental condition.

\section{Materials and Methods}

The finite element model employed in this study included the maxilla and the mandible with associated teeth and periodontal ligaments and a mandibular advancement device (Figure 1). The model was developed according to the dental cone beam computed tomography (CBCT) (Voxel size 75 micron, FOV $11 \times 13 \mathrm{~cm}$. NewTom Giano, Cefla, Italy) images of a 29-year-old female patient. The patient is in good health and does not suffer from OSA or mandibular disorders. Before proceeding with the CT scan, the patient was informed of the purpose of the study and gave her consent to the procedure. Her data were used anonymously in the simulations. The volumetric image of the anatomy was reconstructed in Mimics (v.12.11, Materialise NV, Leuven, Belgium) using an appropriate threshold based on the Hounsfield unit. The periodontal ligaments (PDLs) were reconstructed through the 3D modelling software Rhinoceros (v.5.0 by McNeel \& Associates, Seattle, WA) since soft tissues are not identifiable in CT scans. Although the average thickness of periodontal ligament is 0.15 to $0.38 \mathrm{~mm}$ and it has an hourglass shape (it is thinnest at the middle third of the root [39]), PDLs were modelled by offsetting each tooth root surface of $0.3 \mathrm{~mm}$ to fill the space between each tooth and the alveolar socket $[38,40,41]$. The devices chosen are among the most used in OSA therapy. The authors have selected to consider two different types of mechanics: Lateral and anterior propulsion. In Herbst's $\mathrm{s}^{\mathrm{TM}}$ case, two lateral telescopic arms protrude the mandible. Somnodent ${ }^{\mathrm{TM}}$ also has a lateral mechanism, but the propulsion is no longer given by arms but by two screws that push the wings of the lower splint forward as they move forward. Orthoapnea ${ }^{\mathrm{TM}}$ is an entirely different device that has an anterior inverse connecting rod that is activated through the central screw that produces the protrusion of the mandible. In the simulations, Somnodent ${ }^{\mathrm{TM}}$ was reproduced without vertical elastics that are used to improve the outcome of the therapy. To simulate the effect of different MAD models, three MADs were created through a RE approach starting from the physical prototype due to the personalised nature. An optical laser scanner (Konica Minolta Range 7) was used for digitising a model of MAD to be used as a reference for the design of the two other devices. All the triangular mesh models were further processed and reconstructed to obtain the non-uniform rational basis spline (NURBS) models ready to be imported into Ansys v.19 R1 (Canonsburg, PA, USA) for the final arrangement of the model in terms of material properties, meshing, boundary conditions, and loading conditions. 


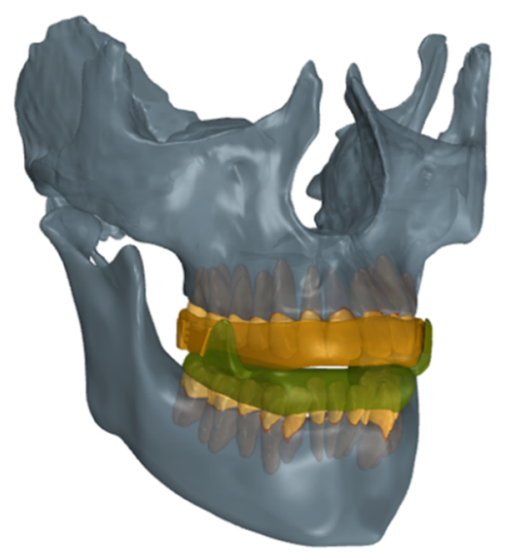

Figure 1. 3D finite element model.

The material properties of teeth and MAD as presented in Table 1 were assumed to be linear elastic, homogeneous, and isotropic. At the same time, a hyperelastic law was used to simulate large non-linear strains associated with the non-linear nature of PDLs [42].

Table 1. Material properties used in the finite element model.

\begin{tabular}{ccc}
\hline Material & Young's Modulus [MPa] & Poisson's Ratio \\
\hline Acrylic MAD & 8300 & 0.28 \\
Tooth & 18,300 & 0.31 \\
\hline
\end{tabular}

A 2nd-order Ogden model was used to define the strain energy function [43-45]. The parameter values listed in Table 2 were obtained through the fitting of uniaxial experimental data by Natali et al. [46].

Table 2. Parameters of the second-order Ogden model.

\begin{tabular}{ccc}
\hline Model & Parameter & Value \\
\hline & $\alpha_{1}$ & -3.4761 \\
& $\alpha_{2}$ & 18.679 \\
Hyperelastic-Ogden & $\mu_{1}$ & -0.034004 \\
& $\mu_{2}$ & 0.00088691 \\
& $\mathrm{~d}_{1}$ & 0 \\
& $\mathrm{~d}_{1}$ & 0 \\
\hline
\end{tabular}

Perfect bonding was assumed between the bodies since MADs are anchored on teeth to force the mandible to a protruded position, and PDLs strongly bind the tooth root to the supporting alveolar bone. Thus, a continuous mesh (shared topology) has been created between MAD and teeth and teeth and PDLs with common nodes at the boundary between the parts. The contact between the bone and the PDL was set as bonded meaning that no sliding or separation is allowed. The two splints of the MAD were coupled in a configuration that will enable mutual sliding without separation. The bony components were assumed as rigid bodies since they have more rigid behaviour than PDLs. Moreover, they were constrained in all directions to prevent rigid body motion.

The authors decided to not differentiate bone in its cortical and cancellous components since the main objective of the study is to compare the results in the three devices. The results, therefore, must be understood as comparative and not in absolute terms.

As a boundary condition, a load associated with the force applied by the MAD to protrude the mandible was applied in the connecting region between the two MAD splints. According to the methodology developed by Bruno et al. [47], it was possible to correlate the amount of advancement 
of the mandible due to the MAD settings to the magnitude of the force exerted by the device and experimentally determined by Cohen-Levy et al. [48]. The application of a pressure transducer to a MAD allowed measuring the force produced by a progressive mandibular advancement. The advancement to which the MADs have been subjected is $9.5 \mathrm{~mm}$, a reasonable value for the treatment of OSA [38]. Thus, an overall force of $11.18 \mathrm{~N}$ was applied on each splint in correspondence of the connection mechanism. The 3D models were then discretised in 5,705,381 linear tetrahedral elements with three degrees of freedom per node. A mean mesh size of $1 \mathrm{~mm}$ was used to discretize the model. A mesh convergence study was performed to ensure the adequacy of the results from the simulation. The obtained numerical solution will tend toward a unique value of Von Mises stress by increasing the mesh density in the PDLs from 0.26 to $0.154 \mathrm{~mm}$. The physical memory of the workstation did not support further mesh refinement $(0.118 \mathrm{~mm})$. Thus, according to the values provided in Table 3 an element size of $0.2 \mathrm{~mm}$ was considered an acceptable trade-off between the quality of the mesh and the computational effort of the workstation. A dense and tight mesh was obtained in the thickness of the bodies ensuring at least two elements in the ligaments' wall.

Table 3. Mesh convergence study.

\begin{tabular}{ccccc}
\hline $\begin{array}{c}\text { Mesh Size } \\
(\mathbf{m m})\end{array}$ & Nodes/Elements & $\begin{array}{c}\text { Von Mises Stress } \\
\mathbf{( M P a )}\end{array}$ & $\begin{array}{c}\text { Elapsed Time } \\
\text { (hour) }\end{array}$ & $\begin{array}{c}\text { Memory Used } \\
\text { (GB) }\end{array}$ \\
\hline 0.26 & $631,362 / 3,317,272$ & $8.07 \times 10^{-3}$ & 3 & 18.972 \\
0.20 & $1,073,911 / 5,706,491$ & $4.26 \times 10^{-3}$ & 22 & 33.212 \\
0.15 & $1,928,454 / 10,404,873$ & $4.48 \times 10^{-3}$ & 36 & 70.366 \\
\hline
\end{tabular}

\section{Results}

In this study, three finite element simulations were carried out by varying the MAD design to analyze the stress distribution and deformation of teeth and PDLs. Tooth movement and pain are the biomechanical response of the stress that develops in teeth and PDLs under the application of a load. Therefore, to evaluate the teeth that are more loaded and the areas that are prone to be compressed and stretched, results in terms of von Mises stress and deformation of teeth and PDLs were presented. (Figure 2).

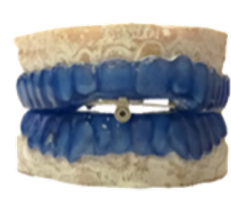

a.

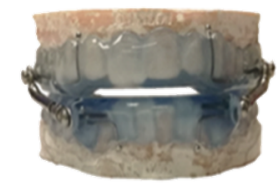

b.

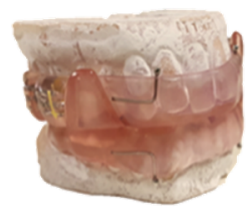

C.

Figure 2. Three models of mandibular advancement devices: OrthoApnea (a), Herbst (b), Somnodent (c).

Regarding the analysis of stress on the periodontal ligaments, significant differences emerge between Orthoapnea ${ }^{\mathrm{TM}}$ (Grupo Dental Ortoplus, Malaga, Spain), Herbst ${ }^{\mathrm{TM}}$ (Somnomed, Sydney, Australia), and Somnodent ${ }^{\mathrm{TM}}$ (Somnomed, Sydney, Australia).

In the case of Orthoapnea ${ }^{\mathrm{TM}}$, which has an anterior reverse rod activation mechanism, the stresses on the individual teeth develop mainly on the coronal portion, while apically, the stresses are minor. The most involved teeth are the lower and upper incisors, with the PDLs exhibiting a maximum expression of strength in correspondence of the anterior cervical margin reaching $4.26 \mathrm{kPa}$ (kilopascal). The teeth of the posterior sectors (premolars and molars) are less stressed. The stresses are slightly uneven in the various portions of the arches, as shown in Figure 3. 
Orthoapnea
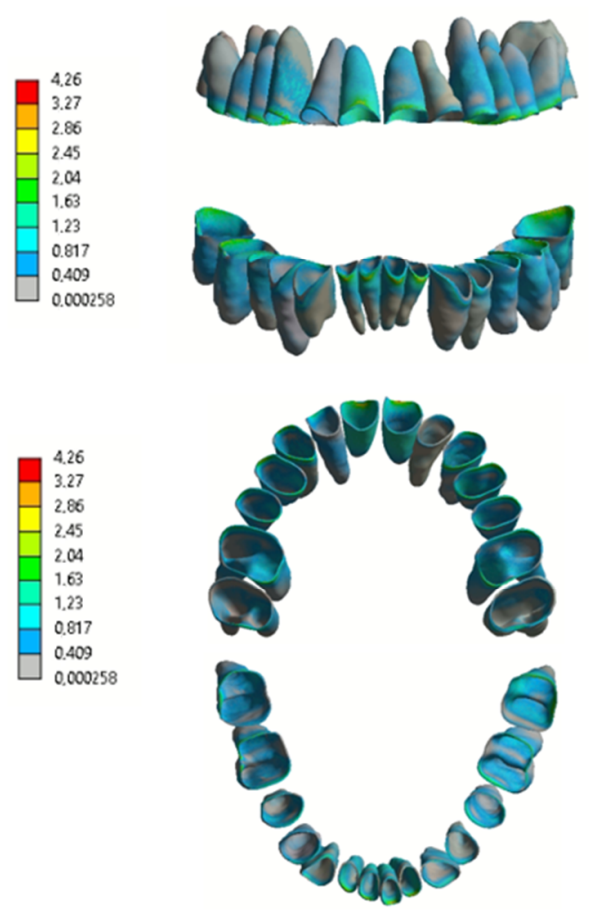

Herbst
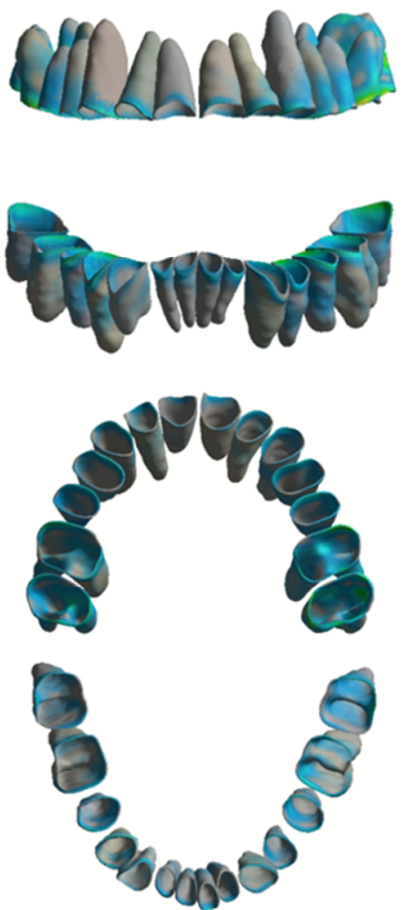

Somnodent
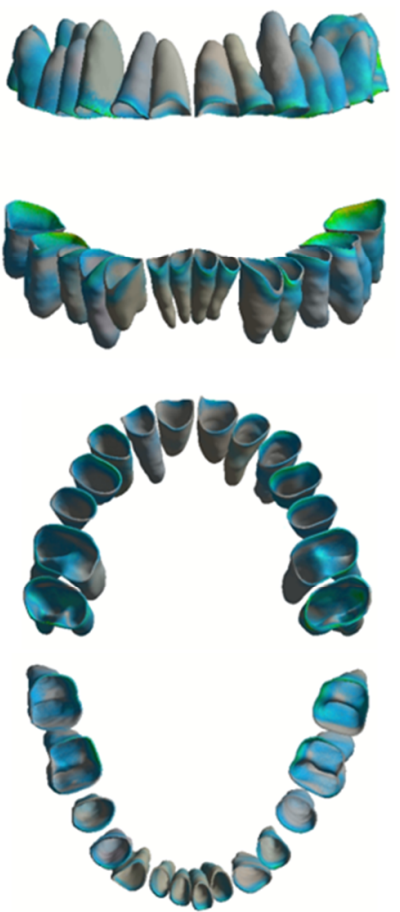

Figure 3. Contour plots. Periodontal ligaments (PDLs) stress distribution (kPa), frontal and occlusal view.

Herbst $^{\mathrm{TM}}$ is a bilateral telescopic activation device. It presents periodontal stresses that are concentrated in the most coronal portion of the teeth similarly to Orthoapnea ${ }^{\mathrm{mTM}}$. The main difference with the first device is that tensions caused by Herbst ${ }^{\mathrm{TM}}$ are much more uniform in the arches. The most stressed teeth are the upper and lower premolars and molars (but the differences are not significant while compared with other teeth). The PDLs are mainly affected by stress in the medio-distal cervical region with a peak of pressure that reaches $3.56 \mathrm{kPa}$.

Somnodent ${ }^{\mathrm{TM}}$ is activated with two lateral propulsion screws and this case also presents concentrated stresses, especially in the coronal portion of the teeth. Stresses are concentrated in the periodontal ligaments of the second molars and, with a minor component, the anterior teeth of both arches. The stress mainly affects the medio-distal cervical sides of PDLs and the lingual sides of mandibular PDLs associated with molars. The maximum pressure achieved is about $3.27 \mathrm{kPa}$. Somnodent ${ }^{\mathrm{TM}}$ is the device that generates the least stresses among the three considered in the study. In Figure 4, the stress analysis of dental elements reflects periodontal tensions. In Orthoapnea ${ }^{\mathrm{TM}}$, the most loaded teeth are the upper and lower incisors. The most affected dental portions are the incisal margins with a maximum value of $600 \mathrm{kPa}$. Herbst ${ }^{\mathrm{TM}}$ has less intense stresses that are concentrated mainly in the maxillary molars and the mandibular premolars. The maximum load value reached is $302 \mathrm{kPa}$. Somnodent ${ }^{\mathrm{TM}}$ has stresses concentrated on the upper molars and mandibular second premolars in correspondence of the splint's wings. The highest pressure is $287 \mathrm{kPa}$. The analyses also allowed us to obtain images, from the occlusal view, representing the stresses and deformations on periodontal ligaments (Figure 3) and teeth (Figure 4). 
Orthoapnea
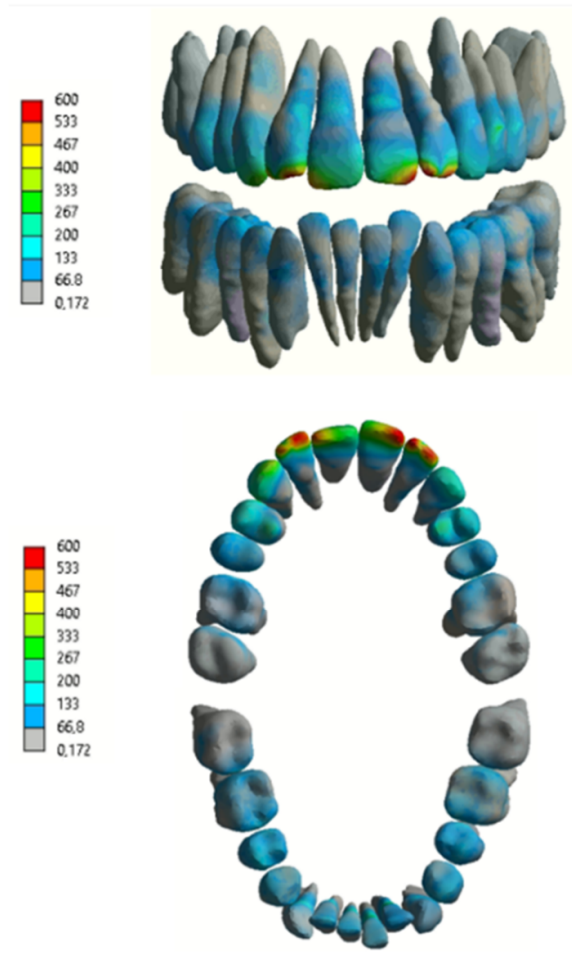

Herbst
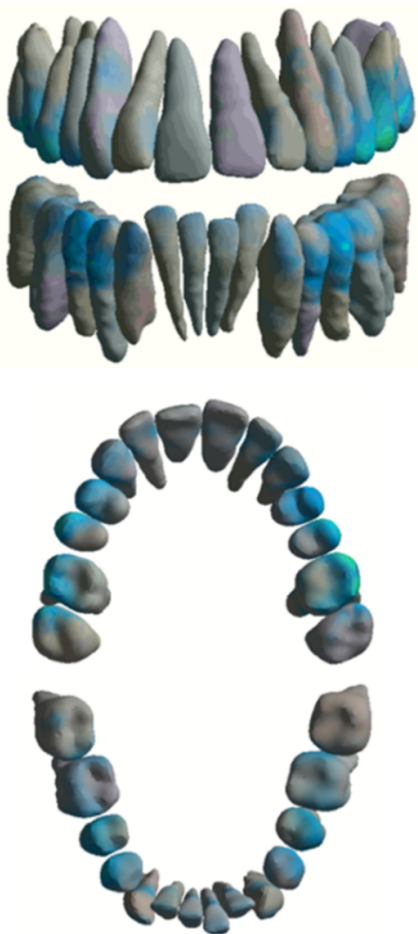

Somnodent
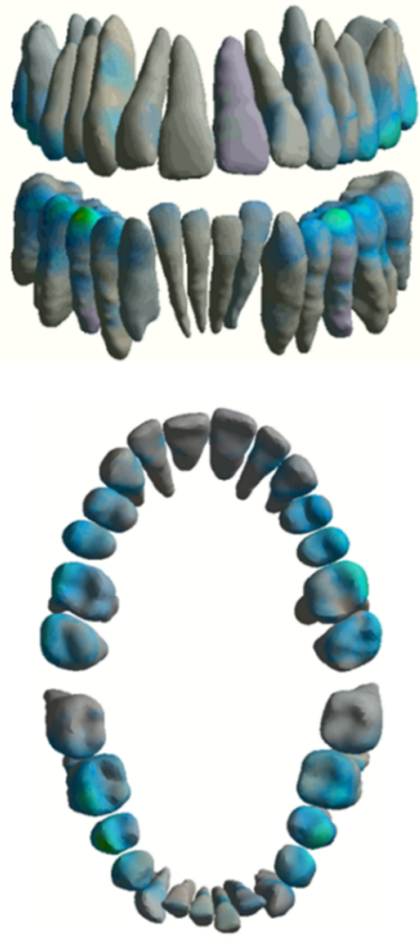

Figure 4. Colour plots. Stress distribution $(\mathrm{kPa})$ in the teeth, frontal and occlusal view.

A lateral representation of the arches shows the deformation vectors to which the individual dental elements of both arches are submitted to (Figure 5). The model shows a right-side view, but the left side is considered symmetrical. In all three devices, the forces tend to displace the teeth of the upper arch downwards and backwards when considering the anterior teeth. In contrast, the deformations on the posterior teeth are directed back and upwards. The deformations are more significant in Orthoapnea ${ }^{\mathrm{TM}}$; in particular, incisor teeth are the most affected teeth, as shown in Figure 5, while the deformations are more uniform in Herbst ${ }^{\mathrm{TM}}$ and in particular in Somnodent ${ }^{\mathrm{TM}}$, which is characterized by the lowest intensity of deformation (Figure 5). This image does not report the advancement of the 9.5 mm MAD at which the simulations were made but is only indicative of the direction of displacement.

Orthoapnea

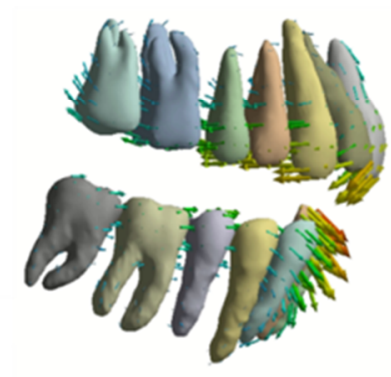

Herbst

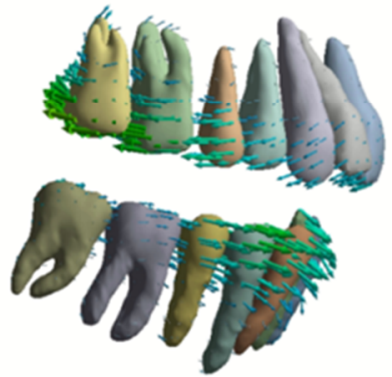

Somnodent

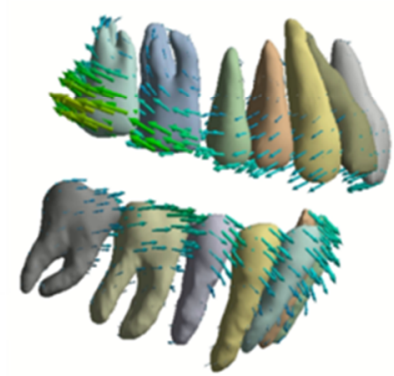

Figure 5. Deformation $(\mathrm{mm})$ on teeth from a lateral view. Arrows indicate the direction of tooth displacement and its intensity (red for higher displacement; blue and grey for lower displacement).

\section{Discussion}

Mandibular advancement devices are efficient in reducing the apnea-hypopnea index (AHI) under the score of 5, a value below which sporadic apnea episodes are considered physiological, in both mild and severe OSA. The resolution of the apneic syndrome is obtained in $48 \%$ of treated patients who 
presented a mild-severe OSA and AHI under 10 in $64 \%$ of the patients, which is considered a good result starting from a severe OSA [18,49]. The reduction of snoring and daily sleepiness, which are the most common symptoms of sleep apnea, is referred in $82 \%$ of patients who wears a mandibular advancement device [50-52].

The effectiveness of MAD therapy has been widely verified in the literature. Still, it is essential also to consider the side effects caused by the treatment. The treatment is indicated for the entire duration of the subject's life. Therefore, as this is not a short-term treatment, the consequences at the dental, skeletal, and articular level have to be taken into consideration. Even though a slight mandibular advancement can also be considered a safe procedure for an extended period and should not cause permanent side effects on the temporomandibular joint [51], dental effects are more evident, resulting in a reduction of both overjet and overbite [53].

Dental displacement is the result of the application of the MAD forces on the attachment system of the teeth and the consequent remodeling at the periodontal level. A study that uses a finite element analysis to investigate the optimal orthodontic force establishes that in a range of orthodontic pressure between $4.7 \mathrm{kPa}$ and $16 \mathrm{kPa}$, dental movements are generated in the biological respect of the periodontal and dental structure [54]. The pressures highlighted by our study turned out to be lower than this range of optimal orthodontic forces. Therefore, a slight tooth movement is obtained, which is compatible with wearing the MAD for long periods. This conclusion is supported by the results of a study showing that occlusal changes (reduction in overjet and overbite) occur in $86.7 \%$ of patients [55]. Another recent research evaluating a 10-year follow-up also demonstrates the presence of dental modifications resulting from the use of MAD; these changes are progressive over time [56]. Given the significant prevalence of the periodontal disease, it is crucial to know the stress levels generated at the level of the individual dental elements in the different types of appliance.

Previous studies investigated the effects of forces applied on periodontal ligaments by orthodontic appliances on both healthy and reduced periodontal attachment. It has been demonstrated that the maximum stress value is located in the ligament portion close to the alveolar crest, because of the pressure generated by the mandibular advancement splint on the arch [57-59].

The analysis found that the Somnodent ${ }^{\mathrm{TM}}$ and Herbst ${ }^{\mathrm{TM}}$ appliances exhibited lower levels of stress than an Orthoapnea ${ }^{\mathrm{TM}}$ device. Orthoapnea ${ }^{\mathrm{TM}}$ releases the activation forces in a concentrated manner on the anterior teeth of both arches. At the same time, Herbst and Somnodent ${ }^{\mathrm{TM}}$ concentrate their stresses on the posterior teeth. This result agrees with a previous study demonstrating a stress concentration at the molars wearing a MAD with the lateral mechanism [38]. The results of the paper agree on a study comparing the dental effects of using a Somnodent ${ }^{\mathrm{TM}}$ device and TAPTM (which is a MAD that has the same mechanics as Orthoapnea ${ }^{\mathrm{TM}}$ ). In the study, it was shown that the dental modifications are lower in the case of Somnodent ${ }^{\mathrm{TM}}$ [60]. According to the authors, the difference depends on the two different mechanics that promote the activation of the three devices. Somnodent ${ }^{\mathrm{TM}}$ has a bilateral activation screw located at the level of the molar teeth, Herbst ${ }^{\mathrm{TM}}$ has two telescopic technology pistons that join the two arches bringing the jaw forward. Even in this case, the point of application of the forces is at the latero-posterior level on both sides. Orthoapnea ${ }^{\mathrm{TM}}$, on the other hand, has an anterior reverse connecting rod, which discharges the forces on the frontal elements of both arches. The advantages of using a device such as Orthoapnea ${ }^{\mathrm{TM}}$ are, in particular, the possibility of having lateral excursions, useful, for example, in the bruxist patient and the ability of the device to force the jaw to advance further if the patient tends to open mouth during sleep. This phenomenon, which is a typical tendence in OSA, decreases the efficiency of MAD (causing mandibular postrotation and retroposition) and, therefore, the effectiveness of the therapy [61,62]. In lateral mechanical devices such as Somnodent ${ }^{\mathrm{TM}}$ or Herbst ${ }^{\mathrm{TM}}$, since there is no real limit to the opening of the mouth, vertical elastics of adequate length and strength can be used to keep the two parts of the splint in contact. The use of elastics is not necessary in the case of OrthoapneaTM, having included this feature in its mechanics. Devices such as Herbst ${ }^{\mathrm{TM}}$ and Somnodent ${ }^{\mathrm{TM}}$, on the other hand, have the advantage of being less 
aggressive with regards to the stresses applied at the periodontal level and therefore represent a better option in the case of periodontally compromised patients in the anterior mandible area.

Since it is not possible to perform an in vivo validation of this study, a comparison of the results with previous studies assessed its reliability. Earlier articles on orthodontic tooth loading and mandibular advancement devices evaluation from both a clinical point [60] of view and an engineering point of view (finite element analysis) [38,57-59] have been taken into account.

A study carried out using FEM simulations has shown that in the case of a reduced periodontium it is necessary to reduce the application of orthodontic forces to generate lower and more uniform stresses that do not worsen the already compromised situation [59]. This result aids practitioners in deciding the type of appliance to be used so that the applied forces are uniform. The forces applied to the MAD do not depend only on the type of device, but also on the degree of activation: Higher activations correspond to higher stresses. In particular, when $70 \%$ of the maximum advance is exceeded, the risk of root resorption begins to increase (PDL pressure exceeds $4.7 \mathrm{kPa}$ ). A study shows that only below $40 \%$ of advancement is safe to avoid root resorption, but this is not a sufficient advancement to obtain the therapeutic effect of MAD [38].

This study provides critical clinical results that may influence the choice of the device. The analysis, however, has some limitations: The stress simulations are static, no load cycles have been performed, so they detach from the model of orthodontic forces applied intermittently. The simulation focuses on the investigation of the response of the periodontal ligament disregarding the effects at the bone level. Since the study is comparative with a focus on the behavior of the three devices, the authors decided to not discriminate bone in its cortical and cancellous components; this represents a limitation of the study, but as future work, the discrimination between cortical and cancellous bone will be considered following the approach proposed by Toniolo et al. [63]. With this improvement, it will be possible to analyze patients suffering from periodontitis (bone resorption and edentulism). The model used to carry out the analyses refers to a young female, without significant temporomandibular or orthodontic problems, not affected by periodontal disease and who has all the dental elements of both arches. In clinical practice, it is difficult to find patients with these characteristics. Therefore, the authors plan to continue the work with analysis on the reduced periodontium and with cases of partial edentulism or implant rehabilitations to make the study more comparable with the cohorts of adult patients with OSA. Other simulations can be performed using different levels of MADs' activation.

\section{Conclusions}

This work represents a step of more complex work for evaluating the effects caused by a mandibular advancement device for OSA treatment. The study, which is based on FEM, allowed authors to assess stress and deformation caused by MADs on periodontal ligaments and teeth surfaces.

The findings of this study suggest that by changing the design of the mandibular advancement device, there is a significant difference in terms of stress between a bilateral propulsion mechanism and an anterior rod system. In the case of the anterior mechanism model, the stresses are much more concentrated and intense in the anterior area, creating a situation that could be contraindicated in patients presenting periodontal problems. In a subsequent study, stress and deformations applied to a patient with a reduced periodontium and partial edentulism can be studied.

Author Contributions: Conceptualization, G.B., A.d.S., A.M. and M.M.; Investigation, M.C. and F.Z.; Methodology, G.B., A.d.S., M.C., D.L. and M.M.; Supervision, A.G.; Validation, A.G.; Writing-original draft, G.B., A.d.S., Francesca Zalunardo, M.C. and M.M. All authors have read and agreed to the published version of the manuscript.

Funding: This research received no external funding.

Conflicts of Interest: The authors declare no conflict of interest. 


\section{References}

1. Laratta, C.R.; Ayas, N.T.; Povitz, M.; Pendharkar, S.R. Diagnosis and treatment of obstructive sleep apnea in adults. CMAJ 2017, 189, 1481-1488. [CrossRef]

2. Mayer, P.; Pépin, J.L.; Bettega, G.; Veale, D.; Ferretti, G.; Deschaux, C.; Lévy, P. Relationship between body mass index, age and upper airway measurements in snorers and sleep apnoea patients. Eur. Respir. J. 1996, 9, 1-9. [CrossRef] [PubMed]

3. White, D.P. Pathogenesis of obstructive and central sleep apnea. Am. J. Respir. Crit. Care Med. 2005, 172, 1363-1370. [CrossRef] [PubMed]

4. Horner, R.L. Contributions of passive mechanical loads and active neuromuscular compensation to upper airway collapsibility during sleep. J. Appl. Physiol. 2007, 102, 510-512. [CrossRef] [PubMed]

5. Destors, M.; Tamisier, R.; Galerneau, L.M.; Lévy, P.; Pepin, J.L. Pathophysiology of obstructive sleep apnea syndrome and its cardiometabolic consequences. Presse Med. 2017, 46, 395-403. [CrossRef]

6. Schwartz, R.N.; Payne, R.J.; Forest, V.I.; Hier, M.P.; Fanous, A.; Vallée-Gravel, C. The relationship between upper airway collapse and the severity of obstructive sleep apnea syndrome: A chart review. J. Otolaryngol. Head Neck Surg. 2015, 44, 32. [CrossRef]

7. Peppard, P.E.; Young, T.; Barnet, J.H.; Palta, M.; Hagen, E.W.; Hla, K.M. Increased prevalence of sleep-disordered breathing in adults. Am. J. Epidemiol. 2013, 177, 6-14. [CrossRef]

8. Heinzer, R.; Vat, S.; Marques-Vidal, P.; Marti-Soler, H.; Andries, D.; Tobback, N.; Mooser, V.; Preisig, M.; Malhotra, A.; Waeber, G.; et al. Prevalence of sleep-disordered breathing in the general population: The HypnoLaus study. Lancet Respir. Med. 2015, 3, 310-318. [CrossRef]

9. Lurie, A. Obstructive Sleep Apnea in Adults; Karger: Basel, Switzerland, 2011.

10. Chowdhuri, S.; Quan, S.F.; Almeida, F.; Ayappa, I.; Batool-Anwar, S.; Budhiraja, R.; Cruse, P.E.; Drager, L.F.; Griss, B.; Marshall, N.; et al. An official american thoracic society research statement: Impact of mild obstructive sleep apnea in adults. Am. J. Respir. Crit. Care Med. 2016, 193, 37-54. [CrossRef]

11. Fleetham, J.; Ayas, N.; Bradley, D.; Fitzpatrick, M.; Oliver, T.K.; Morrison, D.; Ryan, F.; Series, F.; Skomro, R.; Tsai, W.; et al. Canadian thoracic Society 2011 guideline update: Diagnosis and treatment of sleep disordered breathing. Can. Respir. J. 2011, 18, 25-47. [CrossRef]

12. Salmina, D.; Ogna, A.; Wuerzner, G.; Heinzer, R.; Ogna, V.F. Arterial hypertension and obstructive sleep apnea syndrome: State of knowledge. Rev. Med. Suisse 2019, 11, 1620-1624.

13. Gaines, J.; Vgontzas, A.N.; Fernandez-Mendoza, J.; Bixler, E.O. Obstructive sleep apnea and the metabolic syndrome: The road to clinically-meaningful phenotyping, improved prognosis, and personalized treatment. Sleep Med. Rev. 2018, 42, 211-219. [CrossRef] [PubMed]

14. Amra, B.; Rahmati, B.; Soltaninejad, F.; Feizi, A. Screening questionnaires for obstructive sleep apnea: An updated systematic review. Oman Med. J. 2018, 33, 184-192. [CrossRef] [PubMed]

15. Nagappa, M.; Liao, P.; Wong, J.; Auckley, D.; Ramachandran, S.K.; Memtsoudis, S.; Mokhlesi, B.; Chung, F. Validation of the stop-bang questionnaire as a screening tool for obstructive sleep apnea among different populations: A systematic review and meta-Analysis. PLoS ONE 2015, 10, 14-36. [CrossRef] [PubMed]

16. Chiu, H.Y.; Chen, P.Y.; Chuang, L.P.; Chen, N.H.; Tu, Y.K.; Hsieh, Y.J.; Wang, Y.C.; Guilleminault, C. Diagnostic accuracy of the Berlin questionnaire, STOP-BANG, STOP, and Epworth sleepiness scale in detecting obstructive sleep apnea: A bivariate meta-analysis. Sleep Med. Rev. 2017, 36, 57-70. [CrossRef] [PubMed]

17. Lonia, L.; Scalese, M.; Rossato, G.; Bruno, G.; Zalunardo, F.; De Stefani, A.; Gracco, A. Validity of the stop-bang questionnaire in identifying osa in a dental patient cohort. Medicina 2020, 56, 324. [CrossRef] [PubMed]

18. Kapur, V.K.; Auckley, D.H.; Chowdhuri, S.; Kuhlmann, D.C.; Mehra, R.; Ramar, K.; Harrod, C.G. Clinical practice guideline for diagnostic testing for adult obstructive sleep apnea: An American academy of sleep medicine clinical practice guideline. J. Clin. Sleep Med. 2017, 13, 472-477. [CrossRef] [PubMed]

19. De Oliveira, A.C.T.; Martinez, D.; Vasconcelos, L.F.T.; Gonçalves, S.C.; do Carmo Lenz, M.; Fuchs, S.C.; Gus, M.; de Abreu-Silva, E.O.; Moreira, L.B.; Fuchs, F.D. Diagnosis of obstructive sleep apnea syndrome and its outcomes with home portable monitoring. Chest 2009, 135, 330-336. [CrossRef]

20. Su, S.; Baroody, F.M.; Kohrman, M.; Suskind, D. A comparison of polysomnography and a portable home sleep study in the diagnosis of obstructive sleep apnea syndrome. Otolaryngol. Head Neck Surg. 2004, 131, 44-50. [CrossRef] 
21. De Stefani, A.; Bruno, G.; Agostini, L.; Mezzofranco, L.; Gracco, A. Resolution of a Severe Grade of Obstructive Sleep Apnea Syndrome with Mandibular Advancement Device: A Case Report. Sleep Med. Res. 2020, 11, 44-48. [CrossRef]

22. Luzzi, V.; Brunori, M.; Terranova, S.; Di Paolo, C.; Ierardo, G.; Vozza, I.; Polimeni, A. Difficult-to-treat OSAS: Combined continuous positive airway pressure (CPAP) and mandibular advancement devices (MADs) therapy. A case report. Cranio J. Craniomandib. Pract. 2020, 38, 196-200. [CrossRef] [PubMed]

23. Phillips, C.L.; Grunstein, R.R.; Darendeliler, M.A.; Mihailidou, A.S.; Srinivasan, V.K.; Yee, B.J.; Marks, G.B.; Cistulli, P.A. Health outcomes of continuous positive airway pressure versus oral appliance treatment for obstructive sleep apnea: A randomized controlled trial. Am. J. Respir. Crit. Care Med. 2013, 187, $79-87$. [CrossRef] [PubMed]

24. Ferguson, K.A.; Cartwright, R.; Rogers, R.; Schmidt-Nowara, W. Oral appliances for snoring and obstructive sleep apnea: A review. Sleep 2006, 29, 244-262. [CrossRef] [PubMed]

25. Sutherland, K.; Vanderveken, O.M.; Tsuda, H.; Marklund, M.; Gagnadoux, F.; Kushida, C.A.; Cistulli, P.A. Oral appliance treatment for obstructive sleep apnea: An update. J. Clin. Sleep Med. 2014, 10, 15-27. [CrossRef]

26. De Stefani, A.; Bruno, G.; Mezzofranco, L.; Perri, A.; Marchese Ragona, R.; Gracco, A. Multidisciplinary ent-orthodontic treatment in a hypertensive patient affected by severe OSAS. ORAL Implantol. 2018, 11, 59-63.

27. Mickelson, S.A. Oral Appliances for Snoring and Obstructive Sleep Apnea. Otolaryngol. Clin. N. Am. 2020, 53, 397-407. [CrossRef]

28. Ramar, K.; Dort, L.C.; Katz, S.G.; Lettieri, C.J.; Harrod, C.G.; Thomas, S.M.; Chervin, R.D. Clinical Practice Guideline for the Treatment of Obstructive Sleep Apnea and Snoring with Oral Appliance Therapy: An Update for 2015: An American Academy of Sleep Medicine and American Academy of Dental Sleep Medicine clinical practice guideline. J. Dent. Sleep Med. 2015, 11, 773-827. [CrossRef]

29. De Martins, O.F.M.; Chaves Junior, C.M.; Rossi, R.R.P.; Cunali, P.A.; Dal-Fabbro, C.; Bittencourt, L. Side effects of mandibular advancement splints for the treatment of snoring and obstructive sleep apnea: A systematic review. Dent. Press J. Orthod. 2018, 23, 45-54. [CrossRef]

30. Lang, N.P.; Bartold, P.M. Periodontal health. J. Clin. Periodontol. 2018, 89, 9-16. [CrossRef]

31. Savage, A.; Eaton, K.A.; Moles, D.R.; Needleman, I. A systematic review of definitions of periodontitis and methods that have been used to identify this disease. J. Clin. Periodontol. 2009, 36, 458-467. [CrossRef]

32. Eke, P.I.; Page, R.C.; Wei, L.; Thornton-Evans, G.; Genco, R.J. Update of the Case Definitions for Population-Based Surveillance of Periodontitis. J. Periodontol. 2012, 78, 1387-1399. [CrossRef] [PubMed]

33. Holtfreter, B.; Schwahn, C.; Biffar, R.; Kocher, T. Epidemiology of periodontal diseases in the study of health in Pomerania. J. Clin. Periodontol. 2009, 36, 114-123. [CrossRef] [PubMed]

34. Holtfreter, B.; Kocher, T.; Hoffmann, T.; Desvarieux, M.; Micheelis, W. Prevalence of periodontal disease and treatment demands based on a German dental survey (DMS IV). J. Clin. Periodontol. 2010, 37, $211-219$. [CrossRef] [PubMed]

35. Aimetti, M.; Perotto, S.; Castiglione, A.; Mariani, G.M.; Ferrarotti, F.; Romano, F. Prevalence of periodontitis in an adult population from an urban area in North Italy: Findings from a cross-sectional population-based epidemiological survey. J. Clin. Periodontol. 2015, 42, 622-631. [CrossRef]

36. Eke, P.I.; Dye, B.A.; Wei, L.; Slade, G.D.; Thornton-Evans, G.O.; Borgnakke, W.S.; Taylor, G.W.; Page, R.C.; Beck, J.D.; Genco, R.J. Update on Prevalence of Periodontitis in Adults in the United States: NHANES 2009 to 2012. J. Periodontol. 2015, 86, 11-22. [CrossRef]

37. Kushida, C.A.; Morgenthaler, T.I.; Littner, M.R.; Alessi, C.A.; Bailey, D.; Coleman, J., Jr.; Friedman, L.; Hirshkowitz, M.; Kapen, S.; Kramer, M.; et al. Practice parameters for the treatment of snoring and obstructive sleep apnea with oral appliances: An update for 2005. Sleep 2006, 29, 240-243. [CrossRef]

38. Lee, J.S.; Choi, H.I.; Lee, H.; Ahn, S.J.; Noh, G. Biomechanical effect of mandibular advancement device with different protrusion positions for treatment of obstructive sleep apnoea on tooth and facial bone: A finite element study. J. Oral Rehabil. 2018, 45, 948-958. [CrossRef]

39. Chandra, S.; Chandra, S.; Chandra, M.; Chandra, N. Textbook of Dental and Oral Histology with Embryology; Jaypee Brothers Medical Publishers (P) Ltd.: New Delhi, India, 2007.

40. Dorow, C.; Schneider, J.; Sander, F.G. Finite element simulation of in vivo tooth mobility in comparison with experimental results. J. Mech. Med. Biol. 2003, 3, 79-94. [CrossRef] 
41. Ammar, H.H.; Ngan, P.; Crout, R.J.; Mucino, V.H.; Mukdadi, O.M. Three-dimensional modeling and finite element analysis in treatment planning for orthodontic tooth movement. Am. J. Orthod. Dentofac. Orthop. 2011, 139, e59-e71. [CrossRef]

42. Liu, Z.; Qian, Y.; Zhang, Y.; Fan, Y. Effects of several temporomandibular disorders on the stress distributions of temporomandibular joint: A finite element analysis. Comput. Methods Biomech. Biomed. Eng. 2016, 19, 137-143. [CrossRef]

43. Wu, B.; Tang, W.; Yan, B. Study on stress distribution in periodontal ligament of impacted tooth based on hyperelastic model. In Proceedings of the 2009 International Conference on Information Engineering and Computer Science, ICIECS, Wuhan, China, 19-20 December 2009; pp. 1-4.

44. Huang, H.; Tang, W.; Yan, B.; Wu, B. Mechanical responses of periodontal ligament under a realistic orthodontic loading. Procedia Eng. 2012, 31, 828-833.

45. Roostaie, M.; Soltani, M. Mechanical responses of maxillary canine and surrounding tissues under orthodontic loading: A non-linear three-dimensional finite element analysis. J. Braz. Soc. Mech. Sci. Eng. 2017, 39, 2353-2369. [CrossRef]

46. Natali, A.N.; Carniel, E.L.; Pavan, P.G.; Bourauel, C.; Ziegler, A.; Keilig, L. Experimental-numerical analysis of minipig's multi-rooted teeth. J. Biomech. 2007, 40, 1701-1708. [CrossRef] [PubMed]

47. Bruno, G.; De Stefani, A.; Conte, E.; Caragiuli, M.; Mandolini, M.; Landi, D.; Gracco, A. A procedure for analyzing mandible roto-translation induced by mandibular advancement devices. Materials (Basel) 2020, 13, 1826. [CrossRef] [PubMed]

48. Cohen-Levy, J.; Pételle, B.; Pinguet, J.; Limerat, E.; Fleury, B. Forces created by mandibular advancement devices in OSAS patients: A pilot study during sleep. Sleep Breath. 2013, 17, 781-789. [CrossRef]

49. Azagra-Calero, E.; Espinar-Escalona, E.; Barrera-Mora, J.M.; Llamas-Carreras, J.M.; Solano-Reina, E. Obstructive sleep apnea syndrome (OSAS). Review of the literature. Med. Oral Patol. Oral Cir. Bucal 2012, 17, 925-929. [CrossRef]

50. Serra-Torres, S.; Bellot-Arcís, C.; Montiel-Company, J.M.; Marco-Algarra, J.; Almerich-Silla, J.M. Effectiveness of mandibular advancement appliances in treating obstructive sleep apnea syndrome: A systematic review. Laryngoscope 2016, 126, 507-514. [CrossRef]

51. Crivellin, G.; Bruno, G.; De Stefani, A.; Mazzoli, A.; Mandolini, M.; Brunzini, A.; Gracco, A. Strength distribution on TMJ using mandibular advancement device for OSAS treatment: A finite element study. Dent. Cadmos 2018, 86, 757-764. [CrossRef]

52. Lu, R.J.; Tian, N.; Wang, J.Z.; Zou, X.; Wang, J.J.; Zhang, M.; Bai, C.Q.; Yu, K.T. The effectiveness of adjustable oral appliance for older adult patients with obstructive sleep apnea syndrome. Ann. Cardiothorac. Surg. 2020, 9, 2178-2186.

53. Pliska, B.T.; Nam, H.; Chen, H.; Lowe, A.A.; Almeida, F.R. Obstructive sleep apnea and mandibular advancement splints: Occlusal effects and progression of changes associated with a decade of treatment. J. Clin. Sleep Med. 2014, 10, 1285-1291. [CrossRef]

54. Liao, Z.; Chen, J.; Li, W.; Darendeliler, M.A.; Swain, M.; Li, Q. Biomechanical investigation into the role of the periodontal ligament in optimising orthodontic force: A finite element case study. Arch. Oral Biol. 2016, 66, 98-107. [CrossRef]

55. Ueda, H.; Almeida, F.R.; Lowe, A.A.; Ruse, N.D. Changes in occlusal contact area during oral appliance therapy assessed on study models. Angle Orthod. 2008, 78, 866-872. [CrossRef] [PubMed]

56. Uniken Venema, J.A.M.; Doff, M.H.J.; Joffe-Sokolova, D.S.; Wijkstra, P.J.; van der Hoeven, J.H.; Stegenga, B.; Hoekema, A. Dental side effects of long-term obstructive sleep apnea therapy: A 10-year follow-up study. Clin. Oral Investig. 2019, 24, 3069-3076. [CrossRef] [PubMed]

57. Brunzini, A.; Gracco, A.; Mazzoli, A.; Mandolini, M.; Manieri, S.; Germani, M. Preliminary simulation model toward the study of the effects caused by different mandibular advancement devices in OSAS treatment. Comput. Methods Biomech. Biomed. Eng. 2018, 21, 693-702. [CrossRef] [PubMed]

58. Toms, S.R.; Eberhardt, A.W. A nonlinear finite element analysis of the periodontal ligament under orthodontic tooth loading. Am. J. Orthod. Dentofac. Orthop. 2003, 123, 657-665.

59. Jeon, P.D.; Turley, P.K.; Ting, K. Three-dimensional finite element analysis of stress in the periodontal ligament of the maxillary first molar with simulated bone loss. Am. J. Orthod. Dentofac. Orthop. 2001, 119, 498-504.

60. Venema, J.; Stellingsma, C.; Doff, M.; Hoekema, A. Dental Side Effects of Long-Term Obstructive Sleep Apnea Therapy: A Comparison of Three Therapeutic Modalities. J. Dent. Sleep Med. 2018, 5, 39-46. [CrossRef] 
61. Tsuda, H.; Lowe, A.A.; Chen, H.; Fleetham, J.A.; Ayas, N.T.; Almeida, F.R. The relationship between mouth opening and sleep stage-related sleep disordered breathing. J. Clin. Sleep Med. 2011, 7, 181-186. [CrossRef]

62. Kim, E.J.; Choi, J.H.; Kim, K.W.; Kim, T.H.; Lee, S.H.; Lee, H.M.; Shin, C.; Lee, K.Y.; Lee, S.H. The impacts of open-mouth breathing on upper airway space in obstructive sleep apnea: 3-D MDCT analysis. Eur. Arch. Oto-Rhino-Laryngol. 2011, 268, 533-539. [CrossRef]

63. Toniolo, I.; Salmaso, C.; Bruno, G.; De Stefani, A.; Stefanini, C.; Gracco, A.L.T.; Carniel, E.L. Anisotropic computational modelling of bony structures from CT data: An almost automatic procedure. Comput. Methods Programs Biomed. 2020, 189, 105319.

(C) 2020 by the authors. Licensee MDPI, Basel, Switzerland. This article is an open access article distributed under the terms and conditions of the Creative Commons Attribution (CC BY) license (http://creativecommons.org/licenses/by/4.0/). 